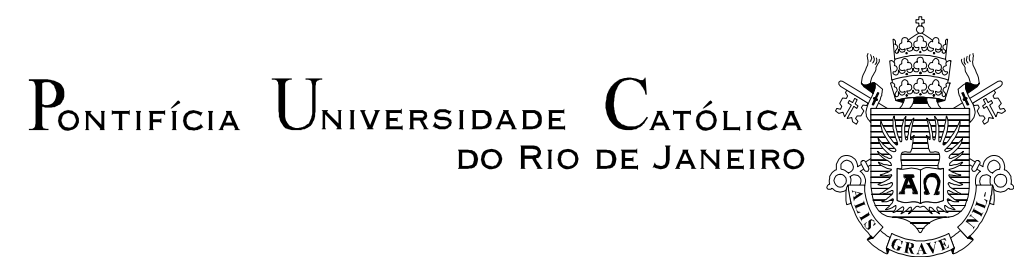

Tomás Mariani Lemos

\title{
Expansão das áreas de favela e de risco em torno do Parque da Tijuca, Rio de Janeiro - RJ
}

\section{Dissertação de Mestrado}

Dissertação apresentada como requisito parcial para obtenção do título de Mestre pelo Programa de PósGraduação em Engenharia Urbana Ambiental da PUC-Rio (Opção Profissional).

Orientador: Prof. Celso Romanel

Co-orientador: Prof. Madiagne Diallo

Rio de Janeiro

Dezembro de 2011 


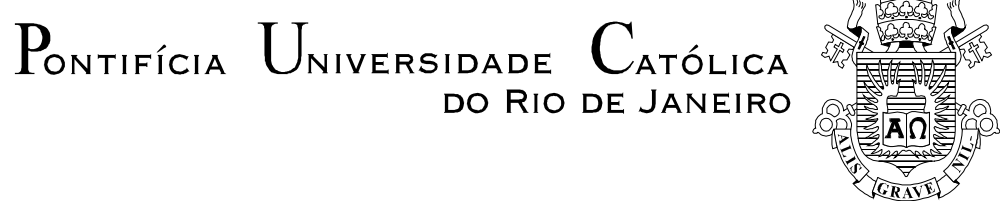

Tomás Mariani Lemos

\title{
Expansão das áreas de favela e de risco em torno do Parque da Tijuca, Rio de Janeiro - RJ
}

Dissertação apresentada como requisito parcial para obtenção do título de Mestre pelo Programa de Pós-Graduação em Engenharia Urbana Ambiental da PUC-Rio (Opção Profissional). Aprovada pela Comissão Examinadora abaixo assinada.

\author{
Prof. Celso Romanel \\ Departamento de Engenharia Civil - PUC-Rio \\ Prof. Magdiane Diallo \\ Co-orientador \\ Departamento de Engenharia Industrial - PUC-Rio \\ Profa. Maria Fernanda Rodrigues Campos Lemos \\ Departamento de Engenharia Civil - PUC-Rio \\ Profa. Aspásia Brasileiro Alcântara de Camargo \\ UERJ \\ Prof. José Eugênio Leal
}

Coordenador Setorial do Centro Técnico Científico - PUC-Rio

Rio de Janeiro, 20 de dezembro de 2011 
Todos os direitos reservados. É proibida a reprodução total ou parcial do trabalho sem autorização da universidade, do autor e do orientador.

\section{Tomás Mariani Lemos}

Graduou-se em Psicologia pela Universidade Federal do Rio de Janeiro em 1994. Pós-graduado em Análise e Avaliação Ambiental pela Pontifícia Universidade Católica do Rio de Janeiro em 1996. Pós-graduado em Especialização e Planejamento e Uso do Solo Urbano pelo Instituto de Pesquisa e Planejamento Urbano e Regional - IPPUR -da Universidade Federal do Rio de Janeiro em 1996. MBA em Gestão Ambiental pela Fundação Getúlio Vargas em 2002. Pós-graduado em Engenharia Urbana e Ambiental pela Pontifícia Universidade Católica do Rio de Janeiro em 2011. Principais áreas de interesse: planejamento urbano, gestão de espaços públicos e a interação homem/ natureza nas ocupações urbanas.

Ficha Catalográfica

Lemos, Tomás Mariani

Expansão das áreas de favelas e de risco no entorno do Parque Nacional da Tijuca, Rio de Janeiro - RJ/ Tomás Mariani Lemos; orientador: Celso Romanel; co-orientador: Madiagne Diallo. - 2011.

$101 \mathrm{f.} ; 30 \mathrm{~cm}$

Dissertação (mestrado) - Pontifícia Universidade Católica do Rio de Janeiro, Departamento de Engenharia Civil, 2011.

Inclui bibliografia

1. Engenharia civil - Teses. 2. Favelas. 3. Ocupação de encostas. 4. Declividade do terreno. 5. Parque Nacional da Tijuca. I. Romanel, Celso II. Diallo, Madiagne. III. Pontifícia Universidade Católica do Rio de Janeiro. Departamento de Engenharia Civil. IV. Título. 
Para Chris, por sempre ter se interessado e me apoiado nesse trabalho.

A minha mãe Glória, que sempre me estimulou a pensar e criticar as condições da cidade onde moramos;

E ao pequeno Gabriel, que chegou me inspirando em ações por um mundo melhor. 


\section{Agradecimentos}

Ao Rafael Nunes e a Danielle Cintra, pelos seus extensos conhecimentos em Geografia e Sensoriamento Remoto.

Aos colegas de curso que ajudaram em assuntos não tão simples para minha compreensão.

E ao Professor MadiagneDiallo, por apoiar este projeto desde o início. 


\section{Resumo}

Lemos, Tomás Mariani; Romanel, Celso (Orientador); Diallo, Madiagne (co-orientador). Expansão das áreas de favela e de risco em torno do Parque da Tijuca, Rio de Janeiro - RJ. Rio de Janeiro, 2011, 101p. Dissertação de Mestrado - Departamento de Engenharia Civil, Pontifícia Universidade Católica do Rio de Janeiro.

Este trabalho trata da expansão urbana no entorno do Parque Nacional da Tijuca, uma área de preservação ambiental dentro da cidade do Rio de Janeiro, centro urbano com cerca de 6.300 .000 habitantes. O objetivo principal foi estudar, através de avaliações feitas com base em imagens de satélite e fotos aéreas de oito favelas vizinhas ao Parque (Borel, Cerro Corá, Complexo do Turano, Mata Machado, Vila Parque da Cidade, Rocinha, Salgueiro e Santa Marta) a modificação ocorrida no uso do solo, entre os anos de 1999 a 2009, principalmente na variação da área edificada e em locais situados acima da cota $100 \mathrm{~m}$ e encostas com declividade do terreno superior a $45^{\circ}$. Com a utilização de programas computacionais de sistemas de informação geográfica e interpretação visual de imagens, foram obtidas importantes conclusões sobre a tendência de expansão das favelas analisadas. Em todas, foram constatadas taxas de crescimento mínimo da ordem de 3,6\% acima da cota $100 \mathrm{~m}$ e da ordem de 1,6\% nas áreas de encostas com declividade acima de $45^{\circ}$, que indicam um agravamento ao risco de escorregamentos de terra ao qual estas populações estão expostas. Em contrapartida, foi também possível observar os bons resultados da política de reflorestamento, constatadas nas variações positivas de área de cobertura vegetal em várias destas favelas, através do programa Mutirão Reflorestamento da Prefeitura da Cidade do Rio de Janeiro, iniciado em 1987.

\section{Palavras-chave}

Favelas; ocupação de encostas; declividade do terreno; áreas de risco; Parque Nacional da Tijuca. 


\section{Abstract}

Lemos, Tomás Mariani; Romanel, Celso (Advisor); Diallo, Madiagne (coAdvisor). The expansion of slums and of risky areas around Parque da Tijuca, Rio de Janeiro - RJ. Rio de Janeiro, 2011, 101p. MSc Dissertation - Departamento de Engenharia Civil, Pontifícia Universidade Católica do Rio de Janeiro.

This workwill focus on the urban expansion around the National Park of Tijuca, an area of environmental protection within the city of Rio de Janeiro, an urban center with a population of approximately 6.300 .000 inhabitants and 1023 registered slums. The main objective is to study, through estimates made using satellite images and aerial photos, the modification in the land use in eight slums situated around the park (Borel, Cerro Corá, Complexo do Turano, Mata Machado, Vila Parque da Cidade, Rocinha, Salgueiro e Santa Marta) during a ten year period from 1999 to 2009. Two specific aspects, concerning new constructions above $100 \mathrm{~m}$ of altitude and on slopes with declivity superior to $45^{\circ}$, will be examined in detail, since they are restrictions provided by law. With the use of geographic information systems and visual interpretation of images, several important conclusions were obtained about the expansion tendency of these slums. In all of them the growing rate was at least $3.6 \%$ above the $100 \mathrm{~m}$ altitude and at least $1.6 \%$ in areas with declivity superior to $45^{\circ}$, indicating that these populations are exposed to serious risks of landslides. On the other hand, it was also possible to notice the good results of the reforestation policy, initiated by the City of Rio de Janeiro in 1987, given the positive variations in the areas of vegetation observed in several of the slums analyzed in this work.

\section{Keywords}

Slums; housing; occupation of hillsides; ground declivity; risk areas; National Park of Tijuca. 


\section{Sumário}

1 Introdução 14

$\begin{array}{lll}1.1 & \text { Justificativas e objetivo } & 14\end{array}$

$\begin{array}{lll}1.2 & \text { Estrutura da dissertação } & 15\end{array}$

2 A ocupação irregular do solo na cidade do Rio de Janeiro 17

2.1 A ocupação irregular do solo nas metrópoles brasileiras 17

2.2 A ocupação irregular do solo no Rio de Janeiro 18

2.3 Ocupação irregular das encostas 20

3 Interpretação de imagens de satélite 23

3.1 Áreas analisadas 23

3.2 Definição das classes 26

3.3 Classes nos anos de 1999 e 2009

3.4 Análise espacial da transformação da paisagem 32

4 Ocupação das encostas por favelas no período 1999 - 2009

4.1 Interpretação visual 35

4.1.1 Favela do Borel 35

4.1.2 Favela Cerro-Corá 39

4.1.3 Complexo do Turano 44

4.1.4 Favela Mata Machado 45

4.1.5 Favela Vila Parque da Cidade 48

4.1.6 Favela da Rocinha $\quad 51$

4.1.7 Favela do Salgueiro $\quad 58$

4.1.8 Favela Santa Marta 59

4.2 Comparação entre as classes de cobertura 62

4.3 Áreas acima da cota 100m e áreas com declividade superior a $45^{\circ} \quad 67$

4.4 Verticalização das favelas 83

5 Conclusões $\quad 87$

Referências bibliográficas $\quad 89$

Apêndice 93 


\section{Lista de figuras}

Figura 3.1 - Localização das favelas onde foi analisada a variação do padrão de cobertura do solo no entorno do Parque Nacional da Tijuca.

Figura 3.2 - Exemplo da Favela da Rocinha demonstrando o levantamento da área de influência de 100 metros em relação ao limite original.

Figura 3.3 - Estruturação da conversão do ambiente vetorial para o ambiente matricial.

Figura 3.4 - Exemplo da criação do Modelo Digital de Triangulação a partir do arquivo de curvas de nível a partir do exemplo do limite da Favela do Borel.

Figura 3.5 - Conversão do ambiente tridimensional para o ambiente matricial e conseqüente reclassificação dos valores da matriz em relação à elevação do terreno (altitude).

Figura 3.6 - Conversão do ambiente tridimensional para o ambiente matricial e conseqüente reclassificação dos valores da matriz em relação à declividade

Figura 4.1 - Classificação visual no presente estudo da cobertura do solo na Favela do Borel nos anos de 1999 e 2009.

Figura 4.2 -: Figura demonstrando as diferentes condições de iluminação ao longo do ano devido à inclinação do eixo de rotação da Terra. No solstício de inverno no Hemisfério Sul, temos os dias mais curtos e as noites mais longas.

Figura 4.3 - Diferentes condições de aquisição da imagem devido ao ângulo de visada do satélite. No momento em que se projeta a imagem no plano, consequentemente, temos que na situação 2 , há um aumento de área, em relação à situação 1 .

Figura 4.4 - Classificação visual no presente estudo da cobertura do solo na Favela Cerro-Corá nos anos de 1999 e 2009.

Figura 4.5 - Destaque no mapa de classificação visual (esquerda) da cobertura de solo na favela Cerro-Corá no ano de 2009 relativa à área onde ocorreu o deslizamento de terra em uma das entradas do túnel Rebouças no ano de 2007 (direita).

Figura 4.6 - Classificação visual no presente estudo da cobertura do solo no Complexo do Turano nos anos de 1999 e 2009.

Figura 4.7 - Classificação visual no presente estudo da cobertura do solo na favela Mata Machado nos anos de 1999 e 2009. 
Figura 4.8 - Classificação visual no presente estudo da cobertura do solo na favela Vila Parque da Cidade nos anos de 1999 e 2009.

Figura 4.9 - Verticalização de edificações na favela da Rocinha (TCMRJ, 2009).

Figura 4.10 - Relação entre o número total de favelas nas áreas de planejamento (AP) e o número daquelas atendidas por POUSOs.

Figura 4.11 - Classificação visual no presente estudo da cobertura do solo na favela da Rocinha nos anos de 1999 e 2009.

Figura 4.12 - Classificação visual no presente estudo da cobertura do solo na favela do Salgueiro nos anos de 1999 e 2009.

Figura 4.13 - Classificação visual no presente estudo da cobertura do solo na favela Santa Marta nos anos de 1999 e 2009.

Figura 4.14 - Mapa geral da variação de cobertura em área edificada, entre os anos de 1999 e 2009, nas oito favelas analisadas.

Figura 4.15 - Mapa indicativo das cotas altimétricas (0 -100m e acima de $100 \mathrm{~m})$ nas oito favelas analisadas no presente trabalho.

Figura 4.16 - Mapa indicativo das declividades das encostas (abaixo e acima $45^{\circ}$ ) nas oito favelas analisadas neste trabalho.

Figura 4.17 - Mapa de susceptibilidade a escorregamentos, destacando a favela Mata Machado completamente inserida em área de média susceptibilidade a escorregamentos.

Figura 4.18 - Mapa de susceptibilidade a escorregamentos, destacando a favela Parque da Cidade quase totalmente inserida em área de alta susceptibilidade a escorregamentos.

Figura 4.19 - Mapa de susceptibilidade a escorregamentos, destacando a favela da Rocinha ocupando áreas de alta, média e baixa susceptibilidade a escorregamentos.

Figura 4.20 - Comparação entre o mapa de transformação para área edificada (presente trabalho) com o mapa de suscetibilidade da Fundação Geo-Rio, com destaque de áreas da favela da Rocinha classificadas como de baixa (área 1) e alta (área 2) suscetibilidade a escorregamentos.

Figura 4.21 - Mapa com pontos de escorregamentos de terra na favela da Rocinha em 2010, com indicação de áreas acima da cota 100m e áreas com declividade superior a $45^{\circ}$.

Figura 4.22 - Destaque no mapa de áreas acima da cota $100 \mathrm{~m}$ e com declividade superior a $45^{\circ}$ do presente trabalho e a área correspondente na favelinha da Rocinha.

Figura 4.23 - Mapa de susceptibilidade a escorregamentos, destacando a favela do Borel ocupando área de alta susceptibilidade.

Figura 4.24 - Mapa com indicação dos pontos de deslizamento, da cota $100 \mathrm{~m}$ e das áreas com declividade superior a $45^{\circ}$ na favela do Borel.

Figura 4.25 - Mapa com indicação dos pontos de deslizamento, da cota $100 \mathrm{~m}$ e das áreas com declividade superior a $45^{\circ}$ na favela do Cerro-Corá. 
Figura 4.26 - Mapa de susceptibilidade a escorregamentos, destacando a favela do Cerro-Corá ocupando área de alta susceptibilidade.

Figura 4.27 - Mapa de susceptibilidade a escorregamentos, destacando o Complexo do Turano ocupando área de alta susceptibilidade.

Figura 4.28 - Mapa com indicação de pontos de deslizamento, das áreas acima da cota $100 \mathrm{~m}$ e das áreas com declividade superior a $45^{\circ}$ no Complexo do Turano.

Figura 4.29 - Imagem de um Modelo Digital de Superfície (MDS) em tons de cinza.

Figura 4.30 - Imagens do campus da PUC-Rio mostrando a inexistência de prédios nas áreas demarcadas em amarelo, em 2008, e a construção de novos prédios, em 2009. As diferenças de altura $\square \mathrm{H}$ no modelo digital de superfície são calculadas automaticamente.

Figura do Apêndice A - Variação de cobertura do solo para área edificada entre os anos de 1999 e 2009 na favela do Borel.

Figura do Apêndice B - Variação de cobertura do solo para área edificada entre os anos de 1999 e 2009 na favela Cerro-Corá.

Figura do Apêndice C - Variação de cobertura do solo para área edificada entre os anos de 1999 e 2009 no Complexo do Turano.

Figura do Apêndice D - Variação de cobertura do solo para área edificada entre os anos de 1999 e 2009 na Favela Mata Machado.

Figura do Apêndice E - Variação de cobertura do solo para área edificada entre os anos de 1999 e 2009 na favela Parque da Cidade.

Figura do Apêndice F - Variação de cobertura do solo para área edificada entre os anos de 1999 e 2009 na favela da Rocinha.

Figura do Apêndice G - Variação de cobertura do solo para área edificada entre os anos de 1999 e 2009 na favela do Salgueiro.

Figura do Apêndice H - Variação de cobertura do solo para área edificada entre os anos de 1999 e 2009 na favela Santa Marta. 


\section{Lista de tabelas}

Tabela 3.1- Dados utilizados na interpretação visual e construção dos mapas.

Tabela 3.2 - Chave de classificação com os padrões espectrais utilizados na interpretação visual das classes de cobertura do solo das ortofotos (1999) e da imagem de satélite (2009) na área de estudo. Fonte: NIMA/SEA, 2010.

Tabela 3.3 - Valores atribuídos às classes nos anos de 1999 e 2009.

Tabela 4.1 - Área ocupada pela favela do Borel entre 1999 e 2009. (Fonte: IPP/SABREN, 2010).

Tabela 4.2 - Área ocupada na favela do Borel por cada uma das classes analisadas no presente estudo.

Tabela 4.3 - Área ocupada pela favela Cerro-Corá entre 1999 e 2009.

Tabela 4.4 - Área ocupada na favela Cerro-Corá por cada uma das classes analisadas no presente estudo.

Tabela 4.5 - Área ocupada pelo Complexo do Turano entre 1999 e 2009.

Tabela 4.6 - Área ocupada no Complexo do Turano por cada uma das classes analisadas no presente estudo.

Tabela 4.7 - Área ocupada pela favela Mata Machado entre 1999 e 2009.

Tabela 4.8 - Área ocupada na favela Mata Machado por cada uma das classes analisadas no presente estudo.

Tabela 4.9 - Área ocupada pela favela Vila Parque da Cidade entre 1999 e 2009.

Tabela 4.10 - Área ocupada na favela Vila Parque da Cidade por cada uma das classes analisadas no presente estudo.

Tabela 4.11 - Área ocupada pela favela da Rocinha entre 1999 e 2009.

Tabela 4.12 - Área ocupada na favela da Rocinha por cada uma das classes analisadas no presente estudo.

Tabela 4.13 - Área ocupada pela favela do Salgueiro entre 1999 e 2009.

Tabela 4.14 - Área ocupada por cada uma das classes analisadas nas imagens nos anos de 1999 e 2009 na favela do Salgueiro.

Tabela 4.15 - Área ocupada pela favela Santa Marta entre 1999 e 2009.

Tabela 4.16 - Área ocupada por cada uma das classes analisadas nas imagens nos anos de 1999 e 2009 na favela Santa Marta. 
Tabela 4.17 - Valores de áreas transformadas em áreas edificadas de 1999 a 2009 nas oito favelas analisadas.

Tabela 4.18 - Variação de área transformada em área edificada (coluna da esquerda) e variação da área física total da favela (coluna da direita) no período 1999 a 2009.

Tabela 4.19 - Áreas situadas acima da cota 100m nas oito favelas analisadas e respectivos percentuais de transformação da cobertura.

Tabela 4.20 - Áreas situadas em encostas com declividade superior a $45^{\circ}$ nas oito favelas analisadas e respectivos percentuais de transformação da cobertura.

Tabela 4.21 - Pontos de deslizamento em áreas acima da cota $100 \mathrm{~m}$ e com declividade superior a $45^{\circ}$ devido à chuva de 05 de abril de 2010.

Tabela 4.22 - Áreas com variação vertical da altura de edificações nas favelas oito favelas estudadas, mais as favelas Tijuquinha e Vidigal. 